\title{
Análise SWOT do Projeto de Extensão Comunidade Ativa do Curso de Turismo da UFMA (Brasil)
}

\section{SWOT Analysis of the Extension Project Comunidade Ativa at Tourism Course in UFMA (Brasil)}

\author{
Saulo Ribeiro dos Santos (SANTOS, S. R. dos) ${ }^{*}$ \\ Pedro Pereira Ferreira Júnior (FERREIRA JÚNIOR, P. P.) ${ }^{* *}$ \\ Leticia Peret Antunes Hardt (HARDT, L. P.) ${ }^{* * *}$
}

\begin{abstract}
RESUMO - O presente trabalho objetiva estudar as forças, oportunidades, fraquezas e ameaças do Projeto de Extensão Comunidade Ativa do Curso de Turismo da Universidade Federal do Maranhão - UFMA, através da ferramenta de Análise SWOT que permite o estudo do objeto tanto interna, quanto externamente, tendo como base o ano 2011. Este estudo caracteriza-se como bibliográfico e documental, de análise descritiva e qualitativa, e também de observações em campo e entrevistas com todos os sujeitos envolvidos no referido projeto. Para tanto, torna-se necessária a discussão acerca da extensão universitária, além da coleta de dados sobre o Projeto Comunidade Ativa, viabilizando a análise dessas informações e conclusões parciais. Dessa forma, verificou-se que o Projeto Comunidade Ativa destaca-se quanto à sua proposta, fazendo com que o curso em questão e a UFMA se aproximem da comunidade local, reconhecendo sua realidade e seus problemas cotidianos. Por outro lado, se concluiu existir um entrave quanto aos investimentos no projeto, considerados irrisórios, que, por sua vez, estavam comprometendo seu desempenho, tornando-se reflexo de um
\end{abstract}

\footnotetext{
* Graduação em Turismo pela Faculdade Atenas Maranhense - FAMA. Pós-Graduando em Educação à Distância pela Faculdade Interativa COC. MBA em Turismo: Planejamento, Gestão e Marketing pela Universidade Católica de Brasília - UCB. Mestrado em Administração e Desenvolvimento Empresarial pela Universidade Estácio de Sá - UNESA. Doutorando em Gestão Urbana pela Pontifícia Universidade Católica do Paraná - PUCPR. Professor Assistente do Curso de Turismo da Universidade Federal do Maranhão - UFMA. Endereço para correspondência: Rua Inácio Lustosa, 647, ap. 41 (São Francisco). CEP. 80510-000 - Curitiba - Paraná (Brasil). Telefone para contato: 41-9674-6062. E-mail: saulosantosma@uol.com.br

** Graduação em Turismo (Bacharelado) pela Universidade Federal do Maranhão - UFMA. Especialização em Metodologia do Ensino Superior pela UFMA e MBA em Gestão Empresarial pela Escola de Negócios Excellence. Graduando do curso de Administração da Universidade Estadual do Maranhão. Trabalha no Ministério da Agricultura, Pecuária e Abastecimento. É técnico em Guia de Turismo (regional) pelo SENAC/MA. Já foi professor contratado da rede estadual de ensino (2010), ministrando aulas das disciplinas Empreendedorismo e Métodos e Técnicas de Pesquisa no Ensino Médio, no curso técnico em Turismo e Hospitalidade. Endereço para correspondência: Avenida dos Portugueses, s./n., Sá Viana, Campus do Bacanga, Departamento de Turismo e Hotelaria. CEP. 65000000 - São Luís - Maranhão (Brasil). Telefone para contato: 98-8135-7714. E-mail: pjtur@yahoo.com.br

*** Graduação em Arquitetura e Urbanismo pela Universidade Federal do Paraná - UFPR. Mestrado em Engenharia Florestal pela UFPR e Doutorado em Engenharia Florestal pela UFPR. Professora Titular (Arquitetura e Urbanismo) e Pesquisadora (Programa de Pós-Graduação em Gestão Urbana) da Pontifícia Universidade Católica do Paraná - PUC-PR. Professora aposentada da UFPR (Arquitetura e Urbanismo). Bolsista de Produtividade em Pesquisa - CNPq. Endereço para correspondência: Rua Imaculada Conceição, 1155, PPGTU, Prado Velho. CEP. 80215-901 - Curitiba - Paraná (Brasil). Telefone para contato: 41-9971-9858. E-mail: lpahardt@gmail.com
} 
planejamento pedagógico e administrativo desconexo que ainda não estava tendo a Extensão em uma concepção ampla como uma das prioridades dentro dessa universidade.

Palavras-chave: Extensão universitária; Projeto Comunidade Ativa; Análise SWOT.

ABSTRACT - This paper aims to study the strengths, weaknesses, opportunities and threats of the Comunidade Ativa (Active Community) Extension Project of Tourism Course at the Federal University of Maranhão - UFMA, through the SWOT analysis tool that allows the study of the object both internally and externally based on year 2011. This study is characterized as bibliographic and documentary, with descriptive and qualitative analysis, and also from field observations and interviews with all those involved in that project. Therefore, it becomes necessary to discuss about the university extension in addition to collecting data on the Comunidade Ativa Project, enabling the analysis of this information and partial conclusions. Thus, it was found that the Comunidade Ativa Project stands out on its proposal, making the course in question and UFMA have an approximation with the local community, recognizing its reality and its everyday problems. Moreover, it was concluded that there was a barrier related to the investment in the project, considered derisive, which was compromising performance of the project, making it a reflex of an unconnected pedagogical and administrative planning and it was not being, in its wide conception, a priority in this university.

Key words: Continuing education. Comunidade Ativa Project. SWOT Analysis. 


\section{INTRODUÇÃO}

A relação das universidades com a sociedade viabiliza-se através da Extensão Universitária, pois o extensionismo é a ferramenta pela qual o corpo acadêmico discentes, docentes e técnico-administrativos - podem reconhecer a realidade local e seus problemas, em busca de soluções, o que proporcionará conhecimentos reflexivos. (CASTRO, 2004; SOUSA, 2001) Essa relação deve ser construída a partir do reconhecimento de que tanto universidade como comunidade possuem seus respectivos saberes, sendo ambas importantes e indispensáveis para a (re)construção do conhecimento e para as transformações sociais.

Verificada a importância da extensão no cenário educacional do Ensino Superior, surgiram algumas indagações geradas a partir de discussões durante a realização do curso de especialização em Metodologia do Ensino Superior em como a extensão realmente contribui para a formação do discente e também para a sociedade, além da contribuição das vivências provindas da monitoria, na época de graduação, no Projeto de Extensão Comunidade Ativa do Curso de Turismo da Universidade Federal do Maranhão - UFMA (Brasil).

O referido projeto trabalha temas relacionados à atividade turística, tendo como público alvo crianças de faixa etária entre 8 e 12 anos de idade. Essas crianças são préselecionadas e estudam no Complexo Educacional Antônio Ribeiro da Silva, escola pública do bairro do Sá Viana, área de entorno da Universidade Federal do Maranhão (UFMA, 2011b).

Destarte, o presente trabalho tem como objetivo geral estudar as fraquezas e fortalezas do projeto Comunidade Ativa, assim como suas oportunidades e suas ameaças em relação ao ambiente externo, através da ferramenta de Análise SWOT. A SWOT é uma ferramenta utilizada para fazer análise de cenário (ou análise de ambiente), já bem difundida entre diversas áreas do conhecimento devido ao seu sistema simples de interpretação. Também é conhecida como Análise F.O.F.A., sigla formada pela tradução da sigla SWOT, do idioma inglês, e é um acrônimo de Forças (Strengths), Fraquezas (Weaknesses), Oportunidades (Opportunities) e Ameaças (Threats). (CHIAVENATO; SAPIRO, 2003). 
O presente estudo é fruto da pesquisa bibliográfica e documental, assim como dos estudos em campo através das técnicas de observação e entrevistas. Caracteriza-se como estudo qualitativo e descritivo, tentando esboçar o cenário e variáveis que se relacionam com o objeto de estudo, no caso, o projeto Comunidade Ativa.

No artigo são trabalhados aspectos sobre a extensão universitária no Brasil, assim como o histórico do Projeto Comunidade Ativa e sua relação com o curso de Turismo. Em seguida traz-se a análise SWOT aplicada no projeto de extensão e por fim as considerações finais.

2 EXTENSÃO UNIVERSITÁRIA: aspectos e discussões fundamentais

Com uma sociedade que respira agilidade, na qual a tecnologia é vetor de desenvolvimento e os meios de comunicação se tornam cada vez mais eficazes, os valores culturais se tornam mutáveis e o presente se distingue do passado de forma cada vez mais veloz. Vive-se um momento singular na história da humanidade, já que o ser social começa a repensar acerca de variadas questões que perpassam tanto por pontos que refletem sobre sua individualidade, quanto a aspectos relacionados à composição do coletivo. O mundo busca respostas sobre dilemas seculares e tenta entender o porquê das mudanças e modificações em sua estrutura social, reavalia uma série de situações, por meio das quais tenta iluminar os caminhos a serem seguidos pelas gerações futuras. Este cenário é descrito por Hobsbawn (1995, p. 562), em que o mesmo faz a seguinte análise:

\begin{abstract}
Vivemos em um mundo conquistado, desenraizado e transformado pelo titânico processo econômico e tecnológico do desenvolvimento capitalista que dominou os dois ou três últimos séculos. Sabemos, ou pelo menos é razoável supor, que ele não pode prosseguir ao infinito. $\mathrm{O}$ futuro não pode ser uma continuação do passado e há sinais de que chegamos a um ponto de crise histórica [...] Nosso mundo corre o risco de implosão [...] Se a humanidade quer ter um futuro reconhecível, não pode ser pelo prolongamento do passado ou do presente. Se tentarmos construir o terceiro milênio nessa base, vamos fracassar. E o preço do fracasso, ou seja, a alternativa para uma mudança da sociedade, é a escuridão.
\end{abstract}

Neste momento atípico, no qual a reflexão torna-se necessária, começa-se a questionar o papel do ser humano enquanto ser social e, principalmente, a função de 
instituições tradicionais consagradas no decorrer da história, tais como: o Estado, a Igreja e a Escola. Inicia-se um processo de discussões que se desenha a partir de indagações acerca da atuação daquelas instituições e qual a sua missão na contemporaneidade, haja vista o cenário dinâmico, de conflito e às vezes contraditório no qual se estabelecem as cenas de ação coletiva.

Com este pano de fundo, questiona-se com maior frequência o verdadeiro papel das instituições educacionais, buscando soluções com relação a aspectos polêmicos tais como: a democratização da educação com qualidade que sirva como base de desenvolvimento social, econômico e humano; o equilíbrio entre as demandas de mercado e os currículos da educação superior; o financiamento das atividades educacionais; o ensino público e seus entraves; a autonomia das instituições educacionais, entre outros. Esta discussão se faz em todos os níveis de ensino, da educação infantil até o nível superior e pós-graduação, sendo necessária uma análise dos modelos e princípios utilizados que possam satisfazer as necessidades e demandas sociais, não sendo marginalizados fatores como ética, democracia e qualidade (FARIA, 2001).

Após o término da primeira década do século XXI, tendo como referência os últimos anos do século anterior, percebe-se um ascendente debate, em especial, sobre a figura das Instituições de Ensino Superior (IES), no que tange a aspectos como missão, visão, infraestrutura, avaliação e qualidade. (CASTRO, 2004). As releituras e análises sobre o Ensino Superior no país vêm mostrar a necessidade de se reavaliar os modelos vigentes que embasam a gestão das universidades, tornando-se fundamental que a sociedade reflita sobre as perspectivas para o futuro daquelas instituições.

Um grande marco teórico no contexto atual é justamente tentar descrever qual a real função das Instituições de Ensino Superior, considerando dilemas e entraves que estão presentes no seu cotidiano, haja vista a influência de fatores de ordem econômica, política e cultural. Para Buarque (1994, p. 225), “todas estas 'crises' geram tensões tanto no relacionamento da universidade com o Estado e a sociedade, como no interior da própria instituição".

A universidade precisa se repensar, colocar a público seu projeto para se fazer entender. Ela é uma instituição da sociedade e a ela tem que se referenciar. Os governos necessitam rever sua postura mediante a universidade, sucateada na estrutura e nos seus valores. Ela não pode 
continuar a viver a mercê dos períodos de maior ou menor sensibilidade das esferas governamentais para com suas questões (CASTRO, 2004, p. 21).

Neste sentido, são presenciadas situações alarmantes relacionadas às referidas instituições, tanto de cunho público quanto privado. Com relação às primeiras, são inúmeros os problemas vivenciados de ordem financeira, estrutural e institucional. Quanto às últimas, com a proliferação de universidades, faculdades e centros de ensino superior da rede particular, a preocupação se dá com a qualidade destes cursos, além da formação de profissionais apáticos e acríticos, voltados somente para questões técnicas, afastando-se da realidade social.

Na própria gestão governamental, independentemente da bandeira partidária, houve tentativas paliativas para solucionar problemas do Ensino Superior, entretanto é notória a falta de planejamento sistêmico para que haja realmente a resolução de questões fundamentais. Enquanto não se apresentam políticas públicas efetivas para a educação superior, resumindo-as somente a instituições de ensino, as universidades, em especial as públicas, vão sendo marginalizadas com estruturas e orçamentos irrisórios, ficando somente no papel suas propostas e projetos, não propiciando o retorno esperado à sociedade.

Todavia, as questões quanto à estrutura institucional são mais preocupantes, já que as universidades deveriam propiciar aos seus alunos e à sociedade uma série de benefícios além do ensino, pois as mesmas possuem responsabilidades amplas que não se resumem à mera reprodução de conhecimento e de informações. Demo (2001, p. 143144,) ressalta uma face obscura das instituições de ensino superior na atualidade que muitos não percebem e outros que não a querem ver:

Espera-se que a universidade não se torne apenas sucursal do mercado, olvidando seus horizontes educacionais e culturais. Ainda assim, o compromisso com a reconstrução do conhecimento faz parte da sua alma, desde sempre. Olhando a cena nacional universitária, esta exigência parece extemporânea, porque, como regra, as universidades não se ligam ao processo de construção do conhecimento. Bastam-se em dar aula. O docente só faz isso: dá aula. Por isso também se inventou o "horista", que é contratado só para isso. Não se espera dele - nem é pago para tanto - que estude, se atualize, produza conhecimento, acompanhe o processo de inovação do conhecimento. Acabamos definindo o professor pela aula, estritamente. Evito falar de "construção do conhecimento", não porque tenha alguma crítica a Piaget, mas porque considero expressão excessivamente forte: normalmente, RECONSTRUÍMOS conhecimento partindo do conhecimento já existente e disponível [...] Manejo próprio, crítico e criativo do conhecimento é, hoje, a vantagem comparativa entre povos e pessoas. É o 
que distingue avançados de outros atrasados: aqueles produzem conhecimento próprio, estes o copiam. Ou, usando uma alegação provocativa: enquanto o Primeiro Mundo pesquisa, o Terceiro Mundo dá aula! A universidade poderia ocupar papel de absoluto destaque, desde que não se reduzisse a reproduzir conhecimento (grifo do autor).

A partir da reflexão de Demo, pode-se concluir que, de forma genérica, as universidades estão se restringindo à função de Ensino, sendo o mesmo muitas vezes questionado acerca de aspectos metodológicos e de qualidade. Algumas universidades se esquecem de trabalhar outras bases como Pesquisa e Extensão, detendo-se somente à reprodução do conhecimento. Consequentemente, neste sistema reprodutivo, os alunos se preocupam em "assistir aulas" e tirar uma boa nota, repetindo na prova o que lhes foi dito. São esquecidos os valores do pensar crítico e reflexivo, sendo passo primordial para a renovação do conhecimento e início de mudanças sociais.

\section{ENTRE A UNIVERSIDADE E A COMUNIDADE: O CASO DO PROJETO DE EXTENSÃO COMUNIDADE ATIVA}

Restringindo-se ao contexto das relações entre universidade e sociedade, a Extensão Universitária é a ferramenta de otimização que aproxima, ou deveria aproximar, as Instituições de Ensino Superior de suas realidades locais, ou seja, das comunidades que as inserem. O extensionismo é uma das razões de ser da universidade e torna-se canal para a comunicação com a comunidade. Esta aproximação e trabalho conjunto fazem com que a universidade se insira na realidade social e tome ciência das mazelas presentes neste cenário, podendo fazer a devida análise destes fatores, além de buscar soluções que façam com que haja a melhoria na qualidade de vida da comunidade. Bernheim (2001, p. 34-35) ratifica estas informações fazendo um panorama da importância das relações entre universidade e sociedade:

[...] la Universidad es una institución al servicio directo de la comunidad cuya existencia se justifica en cuanto realiza una acción continua de carácter social, educativo y cultural, acercándose a todas las fuerzas vivas de la nación para estudiar sus problemas, ayudar a resolverlos y orientar adecuadamente las fuerzas colectivas.

[...] la Universidad no puede permanecer ajena a la vida cívica de los pueblos, pues tiene la misión básica de formar generaciones creadoras, plenas de energía y de fié, conscientes de sus altos destinos y de su indeclinable 
papel histórico al servicio de la democracia, de la libertad y de la dignidad de los hombres.

Percebe-se no discurso acima que a universidade está conectada à sociedade, sendo que desta ação surge a sua missão social que é justamente proporcionar à comunidade ferramentas que possam fazer com que esta se torne um espaço melhor para se viver. Bernheim ressalta a comunhão entre universidade e sociedade, na qual aquela é responsável pela defesa e garantia de valores tais como a democracia, liberdade e dignidade dos homens, considerando ainda a concepção de seu papel somente a partir dessa interação.

Dessa forma, considera-se como marco histórico o mês de abril de 1975, tendo como base legal a Lei $\mathrm{n}^{\mathrm{o}} 5.540 / 1968$, quando foi divulgado o Plano de Trabalho de Extensão Universitária, no qual a extensão universitária é definida como:

\footnotetext{
[...] um subsistema componente do Sistema Universitário, através do qual a Instituição de Ensino Superior estende sua área de atendimento às organizações, outras instituições e população de um modo geral, delas recebendo um influxo no sentido de retroalimentação dos demais componentes, ou seja, Ensino e a Pesquisa. A extensão da Universidade se processa sob a forma de cursos, serviços, difusão de resultados de Pesquisas e outras formas de atuação exigidas pela realidade da área onde a Instituição se encontra inserida ou exigência de ordem estratégica (BRASIL, 1975, p. 1).
}

Percebe-se que ao se estabelecer a quem a extensão deve atender, "organizações, outras instituições e populações de um modo geral", o plano indica em direção de quem se deveria dar um compromisso da universidade, não estando aí a priorizada clientela historicamente atendida pelos cursos de extensão, ou seja, as camadas menos favorecidas (SOUSA, 2001; FARIA, 2001).

Conforme Demo (2001) e Paula e Azevedo (2006), a Extensão deve responder a um desafio da qualidade política na formação universitária, e para isso, deve-se trabalhar algo intitulado por ele como "Política Social do Conhecimento", que seria a garantia à sociedade, especialmente àquela mais excluída, do acesso à capacidade de manejar conhecimentos. Como resultado se teria uma cidadania que sabe pensar e intervir, confrontar-se com a realidade social, escapando do assistencialismo, muitas vezes encontrado em programas sociais de extensão.

Ou seja, ao desconhecer a cultura da população a quem se destina, a extensão universitária se torna antidialógica e manipuladora, indo de encontro às premissas 
freirianas que propõem a quebra dessa verticalidade "coisificadora", na qual o ator é um sujeito e o outro o objeto, para uma relação onde todos possam ser sujeitos atuantes, que agem e pensam criticamente. Assim, representa-se a educação como prática de liberdade:

\footnotetext{
Educar e educar-se, na prática de liberdade, não é estender algo desde a "sede do saber", até a "sede da ignorância" para "salvar", com este saber, os que habitam nesta.

Ao contrário, educar e educar-se, na prática de liberdade é tarefa daqueles que sabem que pouco sabem - por isto sabem que sabem algo e podem assim chegar a saber mais - em diálogo com aqueles que, quase sempre, pensam que nada sabem, para que estes, transformando seu pensar que nada sabem em saber que pouco sabem, possam igualmente saber mais (FREIRE, 2006, p. 25).
}

A Universidade Federal do Maranhão reconhece a importância da extensão universitária para a instituição e seus sujeitos, assim como para a sociedade de forma geral, sendo uma das suas finalidades "promover a extensão, aberta à participação da população, visando à difusão das conquistas e benefícios, resultantes da criação cultural e da pesquisa científica e tecnológica gerada pela instituição" (UFMA, 2011a, p. 19).

Tendo em vista o desenvolvimento da atividade turística no mundo e também sua expressão em nível nacional, regional e local, o estado do Maranhão, assim como a cidade de São Luís, tornam-se localidades que possuem potencialidade para o Turismo, sendo vetor de desenvolvimento econômico, social e cultural.

Seguindo este curso, a Universidade Federal do Maranhão criou o Curso de Turismo através da Resolução No 14/87 - CONSUN (Conselho Universitário), de 24 de setembro de 1987, e seu reconhecimento se deu em 29 de dezembro de 1994, através da Portaria $\mathrm{N}^{\mathrm{o}}$ 1.847, do Ministério de Estado da Educação e Desporto, em função das necessidades de crescimento sociocultural e econômico do estado, caracterizado pelo enorme potencial turístico subutilizado e baixos índices de desenvolvimento social e econômico (UFMA, 2003).

De forma geral, o Curso de Turismo tem como composição pedagógica aspectos relacionados à inter, trans e multidisciplinaridade, viabilizando a educação através da relação construtiva de teoria e prática, estruturada entre a supracitada indissociabilidade entre o Ensino, a Pesquisa e a Extensão, influenciado pelas diretrizes e filosofia que regem os trabalhos da Universidade Federal do Maranhão. 
A partir de uma ideia sistêmica, seguir-se-á para a descrição das atividades e da estrutura do Projeto de Extensão Comunidade Ativa do Curso de Turismo da UFMA, objetivando, através da Análise SWOT, elencar as suas fortalezas e fraquezas, referindo-se ao ambiente interno, e das oportunidades e ameaças, tratando-se do ambiente externo ao projeto. Atualmente, o projeto de extensão em estudo é de responsabilidade do Núcleo de Pesquisa e Documentação em Turismo, sob a coordenação do Professor Mestre Saulo Ribeiro dos Santos, que está à frente do projeto desde o ano de 2007.

Por iniciativa das professoras do Curso de Turismo Conceição Belfort e Kláutenys Delene, em 2003, por meio das discussões do Grupo de Pesquisa e Estudos em Análise Sistêmica e Patrimônio, chegou-se a conclusão da necessidade de maior aproximação da universidade e do curso com a comunidade local, sendo formulado o citado projeto e posteriormente, após tramites burocráticos, deu-se a sua execução. $\mathrm{O}$ mesmo foi reconhecido oficialmente através da Resolução $\mathrm{N}^{\mathrm{o}} 348$ do Conselho de Ensino, Pesquisa e Extensão (CONSEPE), de 27 de maio de 2004. (UFMA, 2011b).

O projeto tinha como público alvo crianças de idade entre 8 e 12 anos que residiam no Bairro do Sá Viana, vizinho da Universidade Federal do Maranhão, campus do Bacanga. O mesmo, desde o seu início, possuía parceria com o Complexo Educacional Antônio Ribeiro da Silva, de onde eram pré-selecionadas as crianças participantes.

As atividades ocorriam às segundas-feiras, das $14 \mathrm{~h} 30$ as $17 \mathrm{~h} 30$, a cada 10 dias nas dependências da UFMA. As reuniões dos discentes participantes e do coordenador eram agendadas semanalmente para o mesmo dia, a partir das $18 \mathrm{~h}$, na sala do projeto que ficava no Prédio do Centro de Ciências Sociais (UFMA, 2011c).

O Comunidade Ativa estendia suas atividades de 4 a 5 meses de acordo com o calendário semestral da UFMA. Todavia, existia uma fase de planejamento que antecedia a execução das atividades, na qual estas eram organizadas e também a sensibilização dos monitores quanto ao projeto. Nesta fase, havia encontros dos monitores com um professor do Curso de Pedagogia da UFMA, no qual se objetivava dar noções aos discentes de práticas pedagógicas e de como trabalhar com crianças. Era um momento de suma importância para o bom andamento do projeto, já que os monitores tinham contato com outro campo do conhecimento. 
Entretanto, antecedendo a fase de planejamento, tem-se a seleção dos monitores. Geralmente, estes eram em quantidade de quatro e foram selecionados através de um processo que envolvia análise do histórico escolar, entrevista e redação dissertativa sobre temática afim. Tomava-se como pré-requisito o aluno estar cursando no mínimo o quarto período do Curso de Turismo ou Hotelaria.

Em 2011, o Comunidade Ativa possuía duas bolsas fornecidas pela PROEX, no valor de $\mathrm{R} \$ 300,00$ cada, sendo que os dois primeiros alunos aprovados no processo seletivo as recebiam como incentivo.

No ano de 2011, o projeto contava com a participação de 25 crianças do bairro do Sá Viana e objetivava sensibilizá-las através de práticas pedagógicas e recreacionais, para questões referentes ao turismo, meio ambiente, patrimônio, ética, cultura, noções de trânsito, higiene, segurança, dentre outras, direcionadas para a cidade de São Luís e com ênfase na participação ativa da comunidade no processo de desenvolvimento turístico (UFMA, 2011b, 2011c).

Para tanto, se fazia necessário abordar aspectos conceituais de turismo, meio ambiente e patrimônio, além de outros conceitos pertinentes; desenvolver e promover ações recreacionais e práticas pedagógicas promovendo a sensibilização das crianças, envolvendo as temáticas abordadas; explanar assuntos históricos, geográficos e patrimoniais sobre a cidade de São Luís; fornecer informações sobre os impactos positivos e negativos decorrentes do turismo e como a comunidade poderia se inserir no âmbito dessa atividade; integrar as crianças com as questões abordadas, de forma que pudessem vir a perceber o papel que desempenhavam, melhorando, dessa forma, a hospitalidade da região; e promover análise crítica dos discentes em Turismo, sobre seus objetivos profissionais da área (UFMA, 2011c).

Assim, torna-se imprescindível avaliar o comportamento das organizações em relação às forças competitivas do mercado, identificando a posição estratégica no setor em que atua. Ao efetuar-se esta avaliação, recorre-se a instrumentos capazes de perceber as características internas organizacionais e do ambiente externo. Estes instrumentos apoiam a tomada de decisão, reduzindo a incidência de erros devidos a ações mal planejadas. O modelo SWOT é um desses instrumentos, que faz a combinação de forças e fraquezas de uma organização com as oportunidades e ameaças provenientes do mercado. 


\section{ANÁLISE SWOT DO PROJETO COMUNIDADE ATIVA}

Para se chegar ao objetivo de estudar as fraquezas, fortalezas, oportunidades e ameaças do Projeto de Extensão Comunidade Ativa do Curso de Turismo da UFMA por meio da ferramenta SWOT, além da pesquisa bibliografia e documental, foi necessário fazer-se uso da pesquisa de campo, valendo-se de técnicas de pesquisa como a observação e entrevistas semiestruturadas, que permitem maior liberdade de expressão aos entrevistados, com os sujeitos envolvidos, tais como alunos do curso de Turismo que eram monitores, em um total de quatro; com o coordenador do citado projeto; com 13 crianças participantes da turma, 2011.1.; com 1 professora das crianças participantes do projeto que estavam estudando no Complexo Educacional Antônio Ribeiro da Silva; e 2 mães que tinham seus filhos no Projeto Comunidade Ativa.

Os dados foram colhidos no decorrer das atividades da Turma 2011.1 do Comunidade Ativa, iniciando-se a pesquisa desde a fase de planejamento, acompanhando-se os encontros até o término do mês de maio, próximo da conclusão dos trabalhos daquele semestre.

Algumas dificuldades foram encontradas no decorrer do trabalho, pois se tentou entrevista com o Prof. Dr. Antonio Luiz Amaral Pereira, então Pró-Reitor de Extensão da UFMA, mas não se obteve êxito devido a sua agenda, fazendo-se do estudo de Souza (2009) para reconhecer suas impressões sobre a Extensão Universitária, além da pesquisa documental para se pudessem ter dados para a análise.

Tendo o Projeto de Extensão Comunidade Ativa como objeto de estudo da Análise SWOT, delimitaram-se os campos entre ambiente externo e interno, conforme ilustrado na figura 1 : 
FIGURA 1 - ANÁLISE AMBIENTAL DO COMUNIDADE ATIVA

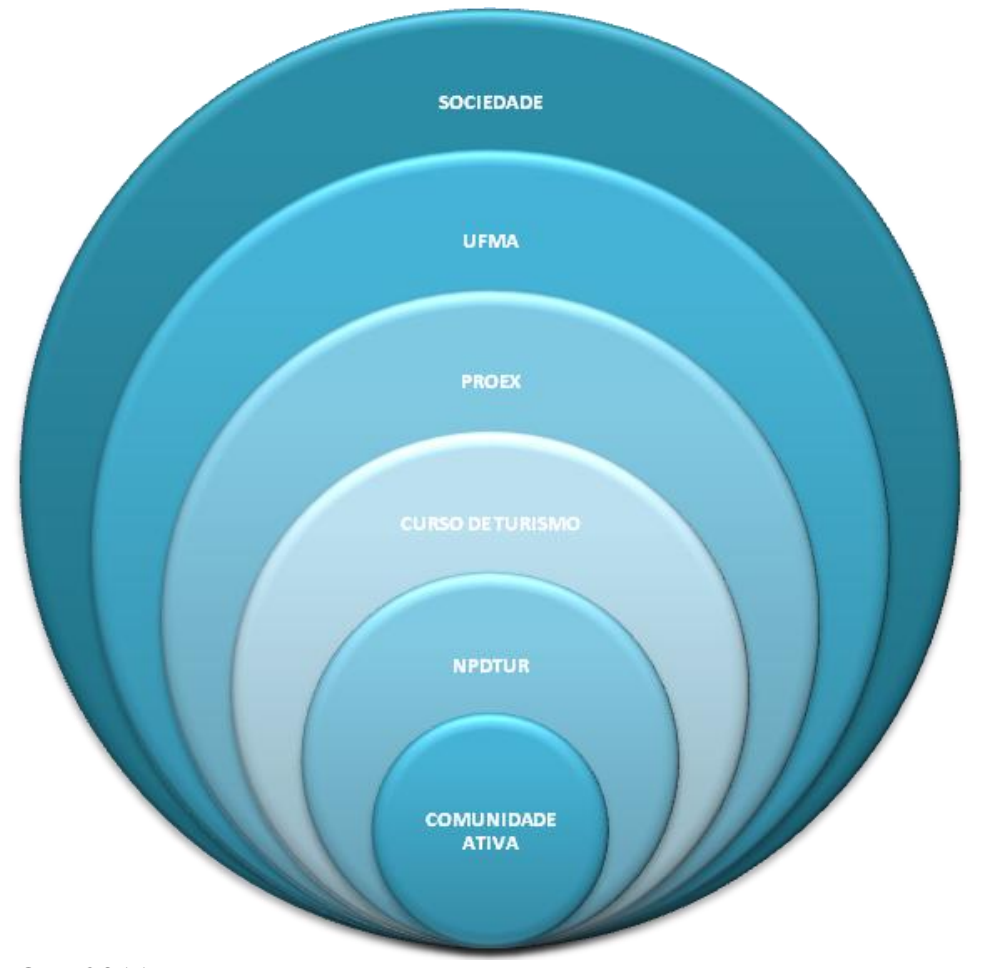

FONTE: AUTOR, 2011.

A partir da figura acima, mostra-se que o ambiente interno do projeto Comunidade Ativa se constitui de todos os recursos materiais e imateriais que fazem com que haja a sua concretização, tais como: materiais de expediente, monitores, crianças participantes, sala de aula, coordenador, lanche, dentre outros.

Quanto ao ambiente externo, situam-se todos os macrocampos que possuem relação direta ou indireta com o Comunidade Ativa como: Núcleo de Pesquisa e Documentação em Turismo, a Coordenação do Curso de Turismo, a Pró-Reitoria de Extensão, a Universidade Federal do Maranhão e a sociedade como um todo, e de forma mais direta o bairro do Sá Viana.

Iniciou-se esta análise a partir do Ambiente Interno, destacando-se as fraquezas e fortalezas detectadas através da coleta de dados. O projeto apresentou possuir muitos pontos fortes, nos quais se destacaram:

a) O histórico favorável que expõe credibilidade com todos os sujeitos envolvidos interna e externamente, como monitores, professores, crianças, pais e escola anfitriã. Em todas as suas edições o projeto obteve resultados satisfatórios, o que permitiu se estender até o primeiro semestre de 2012 (término do projeto), ganhando a confiança na UFMA e nas ruas do bairro Sá Viana. Através da fala das crianças, 
professora e pais, percebeu-se uma impressão positiva acerca da imagem do projeto, vendo-o como oportunidade de crescimento para os participantes. Dentro do curso, o número de alunos que se inscrevem no seletivo do projeto é crescente a cada ano, sendo que através das entrevistas, percebeu-se que os mesmos são motivados principalmente pela busca de experiências, neste caso com a comunidade, além do desenvolvimento de habilidades e adição na carga horária das atividades complementares. A procura a cada ano também é maior pelos pais das crianças, sendo reflexo do bom trabalho feito a cada semestre;

b) Os recursos humanos são aspectos favoráveis ao projeto, pois os monitores e o coordenador mostravam dedicação ao Comunidade Ativa, reservando tempo e esforços para que as atividades fossem executadas com a maior efetividade possível. Os monitores demonstraram possuir habilidades que são indispensáveis para uma boa relação com o público do projeto, exibindo desenvoltura na execução das ações, além de controle nas atividades. Estes possuindo boa comunicação e ótima relação com as crianças do projeto, criando-se vínculos afetivos que foram percebidos em demonstrações em desenhos e no recebimento de pequenos presentes;

c) A diversificação de atividades que envolvem várias habilidades e competências, ocorrendo o desenvolvimento das crianças, é outro fator positivo, já que no planejamento busca-se a maior interação das crianças com a temática trabalhada. Fazendo-se de jogos, brincadeiras, oficinas de desenho e dança, além das exibições de vídeos, os resultados estavam sendo satisfatórios, haja vista a participação das crianças expondo suas experiências e sua impressões sobre o tema do encontro. Neste momento, a equipe que planeja as atividades, coordenador e monitores, assim como as crianças, aprendem, trocam saberes e experiências. Para os monitores este é um momento crucial, pois a partir daí há um engrandecimento do conteúdo aprendido em sala de aula, sendo que estes têm a oportunidade de confrontar estas informações com a realidade que os cerca. Neste momento de troca é que se concretizam as premissas de Paulo Freire, considerando que todos são sujeitos na relação de aprendizagem, já que a equipe do projeto ensina sobre os conteúdos de turismo e as crianças ensinam àqueles sobre sua realidade na comunidade do Sá Viana, ou seja, quem ensina aprende e quem aprende ensina (FREIRE, 2006); 
d) Os passeios, o city tour e as oficinas de danças e teatro, além de outras iniciativas, são técnicas de aprendizagem que buscam aliar teoria e prática. Quando se trabalha cultura popular, a criança pode vivenciá-la em uma oficina, ou reconhecê-la em um museu ou em um passeio que contemple uma manifestação popular, reconhecendo que ela faz parte daquilo, ou seja, ela legitima aquilo como parte de sua cultura, vendo-a com outros olhos e passando a preservá-la. Da mesma forma, nos passeios, as crianças aprendem a partir da experiência que englobam todos os seus sentidos, desde o visual até ao tato. No passeio ao Centro Histórico, as crianças podem conhecer o patrimônio que também é seu, pois só conhecendo é que elas podem preservá-lo. De forma geral, percebeu-se através do diálogo com as crianças nas entrevistas que a maioria nunca tinha visitado os lugares contemplados pelo projeto como o bairro da Praia Grande, que é relativamente próximo do Sá Viana, e também a Lagoa da Jansen. A ida ao cinema foi sempre uma novidade para a maioria que nunca havia tido oportunidade de assistir um filme na "telona". Muitas se emocionavam e ficavam empolgadas com as novidades no parque de diversões, e com certeza, levariam essas vivências para o resto da vida.

e) Em análise das impressões da professora, dos pais e das crianças, percebeu-se que a ação do projeto estava tendo efeito positivo na vida escolar dessas crianças, no qual há o maior interesse pelos estudos, pelas atividades artísticas e pela leitura. Com as oficinas, muitas começaram a melhorar no que diz respeito à exposição oral de suas ideias, participando mais em sala de aula. No espaço escolar as mesmas ficavam mais zelosas quanto à conservação da escola e manutenção de sua limpeza. Em casa, as crianças tornaram-se multiplicadoras das informações quanto à higiene e cidadania;

f) As reuniões semanais são ponto relevante para o bom andamento das atividades, na qual se pode discutir abertamente sobre as ações futuras, além da avaliação que é feita ao término de cada encontro. Segundo os monitores, se criava um espaço para o diálogo entre eles e com o coordenador do projeto, possibilitando a troca de ideias e os melhores resultados possíveis. Os mesmos de forma difundida exteriorizavam que se sentiam desimpedidos para expor suas ideias e que o coordenador fazia com que eles sempre estivessem buscando novos conhecimentos e novas atividades para o projeto.

g) A interação com outros cursos de graduação, como Pedagogia e Odontologia, apareceu como fator relevante, propiciando às crianças e aos monitores o acesso a 
outras áreas do conhecimento e troca de informações. Todavia, o projeto em seu planejamento deve buscar novas possibilidades de contatos com outros cursos, como geografia, história, ciências biológicas, educação física, dentre outros, ampliando assim suas atividades, relacionando-se com outras áreas do conhecimento e aproximando-se mais de uma proposta interdisciplinar.

Este último ponto já se relaciona com as fraquezas do projeto, ou seja, aspectos que devem ser observados e modificados para sua melhoria, dos quais se podem destacar:

a) Interação tímida com outros cursos. A participação dos Cursos de Pedagogia e de Odontologia estava sendo esporádica, considerando que seria importante para o enriquecimento do projeto se estabelecer contato com outros cursos da UFMA. O acompanhamento pedagógico constante também deve ser pensado, com parceria efetiva com o curso de Pedagogia, esperando melhores resultados e maior rentabilidade nas atividades propostas. Se não é possível a participação constante de outros cursos com seus alunos e professores, então que haja momentos de interação mais intensos entre o projeto e outras graduações tanto em sala de aula, quanto nos passeios e visitas;

b) $\mathrm{O}$ fator financeiro apresentou-se como um entrave, já que não se tem uma receita fixa para a manutenção das atividades do projeto Comunidade Ativa. Apesar do valor de manutenção não ser alto, comparado aos efeitos do projeto, não se tinha regularmente o recebimento de verbas, pois a PROEX não repassava nenhum valor ao NPDTUR para tal finalidade. Através de editais do PROEJ/MEC, a coordenação do projeto tentava pleitear verbas para a manutenção das atividades a cada ano, além de iniciativas como bingos e rifas no curso de Turismo. Esporadicamente, eram feitas parcerias que contribuíam de alguma forma com o projeto. Nos últimos anos, teve-se como parceiro do projeto o Box Cinemas (atual Cinépolis) e o Danny’s Park. Esse impasse faz com que as atividades se limitem aos materiais que estão disponíveis, sendo fator determinante para sua execução. Segundo informações do coordenador do projeto, a PROEX se justificava alegando que os materiais utilizados pelo projeto como papel, lápis de cor, cola, cartolinas, tintas, e outros, não são materiais de expediente da UFMA, dificultando a manutenção do projeto neste quesito. Com uma parceria fixa ou manutenção do projeto pela PROEX, certamente os resultados seriam positivos, havendo maior abrangência nas atividades de forma geral; 
c) A oferta de vagas, no caso 25 , já estava se tornando insuficiente para a comunidade do Sá Viana, pois a cada semestre a procura tornava-se maior, mas por questões de recursos de ordem financeira e humana, o projeto tem mantido o mesmo número de crianças participantes a cada período. Este fato é reflexo da alínea 'b' exposta, já que não se tem um mantenedor fixo em termos financeiros, além do número de bolsas ofertadas ao projeto pela PROEX ser reduzido;

d) Por muitas edições do projeto, o Comunidade Ativa não possuía nenhuma bolsa de Extensão. Em diversos anos a Pró-Reitoria de Extensão ofertava a este projeto duas bolsas, no valor de $\mathrm{R} \$ 300,00$ cada. Entretanto, em número de quatro os monitores, ou seja, somente os dois primeiros colocados no processo seletivo do projeto é que são bolsistas. Em entrevista com o coordenador do projeto, ele disse que este fato não atrapalhava as atividades, mas o ideal seria que se tivessem quatro alunos bolsistas. Contudo, o mesmo ressaltou que no período de realização do projeto não via possibilidades da ampliação do número de bolsas pela PROEX para o Comunidade Ativa;

e) Nas primeiras edições do projeto, o mesmo tinha frequência semanal, mas por questões de escassez de recursos financeiros e humanos, o projeto se tornou quinzenal. Caso a proposta inicial retornasse, obter-se-iam resultados ainda melhores, já que o contato com as crianças se daria em menor espaço de tempo, aumentando o número de encontros e atividades, podendo até se incluir novas temáticas. Todavia, na fala do coordenador do projeto, verificou-se que essa proposta tornava-se inviável para o momento devido ao contexto que o projeto se encontrava com o impasse, principalmente, financeiro, já que essa medida implicaria no dobro de recursos e talvez, em mais monitores;

f) Não houve documentação e registro das atividades no decorrer das edições do projeto, o que ocasiona a perda da memória de forma sistematizada de suas ações. Com o atual coordenador, iniciou-se de forma mais efetiva o registro da memória do projeto com a elaboração de relatórios que abordam as atividades de cada semestre, o número de crianças participantes e os resultados obtidos. Todavia, um trecho da história do Comunidade Ativa se perdeu, não podendo se acompanhar com exatidão a sua evolução no decorrer dos tempos; 
Em relação ao ambiente externo, a partir dos dados coletados em fontes documentais, na pesquisa de campo e entrevistas, perceberam-se as seguintes oportunidades ao projeto de Extensão Comunidade Ativa:

a) A receptividade ao projeto por parte do Curso de Turismo, do Departamento de Turismo e Hotelaria, e de forma mais expressiva, pela comunidade do Sá Viana, garantindo assim suas edições futuras;

b) O cenário geral das políticas públicas do Ensino Superior que lentamente estão se desenvolvendo e dando a devida importância à Extensão Universitária, deixando-a no mesmo patamar do Ensino e da Pesquisa. A concepção de que cada vez mais se torna essencial que a universidade se aproxime da comunidade local, tendo como consequência o desenvolvimento de mais projetos e programas de Extensão no país;

c) A possibilidade de bolsas para os monitores via outras instituições, tais como a Fundação de Amparo à Pesquisa e ao Desenvolvimento Científico e Tecnológico do Maranhão (FAPEMA);

d) A parceria com outras instituições privadas ou públicas como forma de manutenção e auxílio ao projeto;

e) A boa relação com o Complexo Educacional Antônio Ribeiro da Silva, parceiro que viabiliza todo o suporte para o contato com os pais e para a seleção das crianças;

f) As metas da UFMA, através da PROEX, eram as de aumentar o valor e o número de bolsas, além do quantitativo de programas e projetos de Extensão;

Entretanto, na Análise SWOT do Comunidade Ativa foram identificadas as seguintes ameaças, em relação ao ambiente externo:

a) Quanto ao Núcleo de Pesquisa e Documentação em Turismo, a Extensão Universitária não está claramente expressa no seu Regime Interno, dentro dos seus objetivos ou descrição de suas responsabilidades. Contudo, o projeto em questão está sobre a responsabilidade deste Núcleo, sendo necessária a inclusão da Extensão no regimento interno;

b) Quanto ao Curso de Turismo, percebeu-se que, como já dito, nos corredores o projeto tinha excelente imagem dentro da academia. Entretanto, alguns entraves aconteceram na Coordenação do curso, pois era eleito um coordenador do projeto, 
sendo que os demais professores se isolavam das atividades relacionadas ao mesmo, não havendo nenhum tipo de trabalho conjunto. Essa relação é fundamental para se tentar aproximar o Ensino, a Pesquisa e a Extensão. Deveria haver um planejamento pedagógico que viabilizasse o trabalho conjunto de diversas disciplinas e que se pudessem integrar alunos, professores e conteúdo programático junto à prática extensiva, que por sua vez, se aproximaria da comunidade local.

De fato não é tarefa fácil reverter esse cenário, já que se tem dentro das universidades quadro reduzido de profissionais, que têm que se dividir em múltiplas funções. No entanto, ainda assim, deve se buscar alternativas para se reverter essa situação. No objeto em estudo, por exemplo, têm-se temáticas diretamente ligadas aos conteúdos curriculares, então existe um vínculo que pode ser trabalhado, através do convite aos professores dessas disciplinas afins que junto com a equipe do projeto, organizariam atividades que pudessem integrar a sala de aula e a Extensão. Neste quesito, o grande desafio era a alteração de posturas, que muitas vezes, mostravam-se cômodas e características do "mesmismo";

c) No Projeto Político Pedagógico do Curso de Turismo, percebeu-se a ausência da Extensão no objetivo geral do mesmo, ressaltados apenas o Ensino e a Pesquisa. Portanto, há necessidade de reavaliação de alguns pontos deste documento, viabilizando a maior representatividade da Extensão dentro dos trabalhos pedagógicos, assim como a sua aproximação com as demais funções acadêmicas;

d) A relação tímida da Pró-Reitoria de Extensão com o projeto em estudo é fator agravante, já que o vínculo com a PROEX se dá somente pelo fornecimento de duas bolsas de Extensão. Não existe nenhum outro tipo de contato formal ou informal, não ocorrendo visitas e acompanhamento pela parte competente, a não ser a emissão de relatórios da coordenação do projeto extensivo.

Neste contexto, há um afastamento do que está expresso no Projeto Político Pedagógico do Curso de Turismo, no qual se destaca que:

[...] Tendo como base a busca da unidade entre ensino, pesquisa e extensão, as práticas investigativas demonstram para os alunos as relações socioculturais, políticas e ambientais que ocorrem de fato quanto ao desenvolvimento turístico, permitindo, assim, que ele formule alternativas para resolver problemas e que retorne a solução para a sociedade, criando um vinculo de cooperação entre universidade e comunidade.

A realização das pesquisas será incentivada e orientada pelos professores do Curso de Turismo, nas atividades que compõem o planejamento das suas 
disciplinas, nas atividades extraclasses e na realização de projetos de pesquisa.

A UFMA através das suas Pró-reitorias de Extensão e de Pesquisa podem dar o apoio necessário para atingir os objetivos propostos (UFMA, 2003, p. 63).

Analisa-se que esta unidade entre Ensino, Pesquisa e Extensão não se efetivou nas práticas pedagógicas do curso em questão, sendo que por um lado professores e alunos pesquisam, outros ministram aulas e outros participam da Extensão, não havendo nenhum contato, troca de ideias e trabalho conjunto. Quanto ao último parágrafo, contase com o auxílio e apoio das Pró-Reitorias competentes, entretanto, as mesmas mostram um trabalho administrativo fragmentado e parcial;

e) Conforme exposto no tópico anterior, o fato de haver uma grande concentração dos programas e projetos de Extensão da PROEX somente em uma área do conhecimento, que por sua vez refletia na distribuição das bolsas de Extensão, faz com que essa situação seja um empecilho para o desenvolvimento da Extensão Universitária em outros campos do conhecimento, consequentemente, do projeto aqui estudado. Ressalta uma reflexão por parte do quadro gestor da UFMA quanto à sua postura acerca desse entrave, tentando dar oportunidade de forma igualitária a todos os centros de conhecimento, além de viabilizar um trabalho conjunto, interdisciplinar e dialógico entre os mesmos. Para tanto, isso requer mudanças quanto aos modelos de administração que envolvem questões institucionais internas e externas.

A partir do cenário desenhado pela Análise SWOT, no qual foi possível identificar algumas fortalezas e fraquezas do projeto, além das oportunidades e ameaças em relação ao ambiente externo, verificou-se que o Comunidade Ativa já era referência no Curso de Turismo e na Universidade Federal do Maranhão como projeto de Extensão. O mesmo é articulador entre a aproximação do referido curso com seus professores e alunos com a comunidade local, ou seja, bairro do Sá Viana.

Nesta relação, de troca de experiência que propicia aprendizado para ambas as partes, de um lado os participantes da comunidade local, que conhecem os conteúdos trabalhados e também a universidade vizinha, por outro, dos alunos e professores que conhecem a realidade na qual os participantes do projeto estão inseridos.

Entretanto, apesar do projeto ter inúmeras qualidades, um percurso histórico admirável, sendo vetor de modificação na vida dos sujeitos envolvidos, direta ou 
indiretamente, este detinha alguns entraves, no quais se percebe sua relação de causaefeito com as suas ameaças, ocasionadas pelo ambiente externo.

Para que haja a minimização das fraquezas do projeto, e consequente maximização das fortalezas, deve-se principalmente traçar estratégias para combater as ameaças. Neste caso, principalmente, a Universidade Federal do Maranhão deve reconhecer de forma efetiva a Extensão como tão importante como a Pesquisa e o Ensino, viabilizando a unificação destas funções através de suas ações administrativas e institucionais. Observou-se haver na UFMA algumas iniciativas, mas que ainda fazem parte de um planejamento pedagógico e administrativo desconexo, afastado de uma concepção extensionista ampla. A mudança de postura é fundamental para que se possa pensar na Extensão Universitária como prioridade dentro desta instituição, o que requer um planejamento em longo prazo, mas com atitudes que se dão a partir de hoje.

Diante do exposto, verifica-se que nessa visão sistêmica, concebe-se uma relação direta entre as partes envolvidas, fazendo com que sejam necessárias mudanças tanto de âmbito interno, quanto externo ao projeto. Essa nova postura propiciará melhores resultados ao Comunidade Ativa, tornando seus efeitos mais enérgicos aos professores, alunos e comunidade local.

Torna-se árduo o processo no qual se possibilitará mudanças mais profundas, mas é fundamental que haja uma reflexão e avaliação contínua das ações institucionais da UFMA no que se refere à Extensão, garantindo assim maior amplitude das concepções de extensionismo e sua prática, otimizando as relações com a sociedade de forma geral.

Por fim, percebe-se que a UFMA através do projeto de Extensão Comunidade Ativa e outros, mostra-se à sociedade, proporcionando o devido retorno a esta, fazendo com que a intensificação dessas relações seja proveitosa para ambas as partes. Deste modo, a UFMA justifica sua razão de existir, possibilitando uma melhoria social significativa à comunidade local. 


\section{CONCLUSÃO}

Diante do exposto, verificou-se que nessa visão sistêmica, concebe-se uma relação direta entre as partes envolvidas, fazendo com que sejam necessárias mudanças tanto de âmbito interno, quanto externo ao projeto. Essa nova postura poderia propiciar melhores resultados ao Comunidade Ativa (finalizado em 2012.1) ou a qualquer outro projeto, tornando seus efeitos mais enérgicos aos professores, alunos e comunidade local.

Destarte, o extensionismo torna-se matéria para discussões e reflexões no âmbito acadêmico, social e político, considerando que sua aplicabilidade efetiva dentro das Instituições de Ensino Superior vira algo complexo e que exige um planejamento pedagógico e administrativo integrado e sistêmico, a partir das premissas estabelecidas.

Neste cenário, para que se possa desenvolver a Extensão Universitária na UFMA de forma integrada a outras funções acadêmicas, incluindo diversos campos do conhecimento, deve haver uma reflexão quanto a algumas posturas desta universidade, além da reestruturação institucional, colocando o extensionismo no mesmo patamar do Ensino e da Pesquisa.

Todavia, percebeu-se que o projeto Comunidade Ativa tem oportunidades para o seu maior desenvolvimento, haja vista as possibilidades de parcerias que outras instituições de cunho público ou privado, além da sua ótima relação com a sociedade, de forma direta, com os sujeitos participantes que residem no bairro do Sá Viana como as crianças, seus pais e professores.

Apesar dos entraves que cercam o Comunidade Ativa, o mesmo, no decorrer de sua trajetória, mostra resultados satisfatórios que poderiam ainda ser maximizados, sendo vetor de transformação na vida de todos os sujeitos participantes. Quanto ao professor e aos alunos participantes que ampliam seus conhecimentos quanto ao conteúdo programático, além do acesso à realidade cotidiana da comunidade local que cerca a UFMA. Quanto às crianças participantes que têm acesso a novos conhecimentos, espaços e experiências, o projeto buscou tornar para elas inesquecível as suas experiências de participação no projeto, fazendo com que as mesmas pudessem ter novas visões, posturas e perspectivas. 
Por fim, ao término do presente trabalho, tem-se ciência de que toda pesquisa é inacabada haja vista o surgimento de novos porquês no seu andamento, possibilitando a sua continuidade e ampliação. Todavia, espera-se que com o alcance desta proposta, tenha contribuído de alguma forma para a reflexão e possíveis mudanças em diversos âmbitos e quanto aos sujeitos aqui envolvidos, somando-se ao desenvolvimento do conhecimento científico e a transformação social.

\section{REFERÊNCIAS}

BERNHEIM, C. T. El nuevo concepto de la extensión universitária. In: FARIA, D. S. de. Construção conceitual da extensão universitária na América Latina. Brasília: Universidade de Brasília, 2001.

BRASIL. Ministério da Educação e da Cultura. Departamento de Assuntos Universitários. Plano de Trabalho de Extensão Universitária. Brasília, 1975.

BUARQUE, C. A aventura da universidade. São Paulo: Ed. UNESP, 1994.

CASTRO, L. M. C. A universidade, a extensão universitária e a produção de conhecimentos emancipadores: ainda existem utopias realistas. Rio de Janeiro, 2004, 185 p. Tese apresentada à Universidade do Estado do Rio de Janeiro do Instituto de Medicina Social para obtenção do grau de Doutor em Saúde Coletiva. Disponível em: <http://www.anped.org.br/reunioes/27/gt11/t1111.pdf>. Acesso em: 03 03/01/2011.

CHIAVENATO, I.; SAPIRO, A. Planejamento estratégico: fundamentos e aplicações. 1. ed. 13. Rio de Janeiro: Elsevier, 2003

DEMO, P. Lugar da extensão. In: FARIA, D. S. de. Construção conceitual da extensão universitária na América Latina. Brasília: Universidade de Brasília, 2001.

FARIA, D. S. de. Construção conceitual da extensão universitária: uma conclusão dêsautor-izada. In: FARIA, D. S. de. Construção conceitual da extensão universitária na América Latina. Brasília: Universidade de Brasília, 2001.

FREIRE, P. Pedagogia da autonomia: saberes necessários à prática educativa. 34. ed. São Paulo: Paz e Terra, 2006.

HOBSBAWN, E. A era dos extremos. São Paulo: Companhia da Letras, 1995.

PAULA, M. de F. C. de; AZEVEDO, M. D. de. Políticas e práticas de privatização do público na universidade: o caso UFF. Revista da Rede de Avaliação Institucional da Educação Superior, Campinas, v. 11, n. 3, p, 91-111, set. 2006. 
SOUSA, A. L. L. Concepção de extensão universitária: ainda precisamos falar sobre isso? In: FARIA, D. S. de. Construção conceitual da extensão universitária na América Latina. Brasília: Universidade de Brasília, 2001.

SOUZA, D. dos S. A contribuição do projeto de extensão comunidade ativa para a formação das crianças participantes do bairro do Sá Viana. 2009. 87 f. Trabalho de Conclusão de Curso (Graduação em Turismo - Universidade Federal do Maranhão, São Luís, 2009.

UFMA. CONSEPE, 2004.

UFMA - UNIVERSIDADE FEDERAL DO MARANHÃO. Plano de metas 2011. São Luís, 2011a.

- Departamento de Turismo e Hotelaria. Curso de Turismo. Projeto Comunidade Ativa. São Luís, 2011 b.

Departamento de Turismo e Hotelaria. Curso de Turismo. Projeto Político Pedagógico do Curso de Turismo. São Luís, 2003.

Relatório de gestão 2010. São Luís, 2011c.

Recebido em: 27-10-2012

Aprovado em: 26-11-2012 